\title{
S-Allyl Cysteine Mitigates Kidney Dysfunctions in the Rat Models of Preeclampsia and Eclampsia: The Possible Role of TNF- $\alpha$ and IL1- $\beta$
}

\author{
Amin Abdollahzade Fard ${ }^{1,3}$ (D), Ehsan Saboory ${ }^{2 *(D)}$, Abdolrahman Biabangard ${ }^{3}(D)$ \\ Mohammad Amini ${ }^{3}$ iD
}

\author{
1. Nephrology and Kidney Transplant Research Center, Clinical Research Institute, Urmia University of \\ Medical Sciences, Urmia, Iran. \\ 2. Zanjan Metabolic Diseases Research Center, Zanjan University of Medical Sciences, Zanjan, Iran; \\ 3. Dept. of Physiology, Faculty of Medicine, Urmia University of Medical Sciences, Urmia, Iran. Biabangard
}

\section{Article Info \\ 10.30699/jambs.29.137.324 \\ Received: 2020/11/22 \\ Accepted: 2021/06/01; \\ Published Online: 01 Aug 2021; \\ Use your device to scan and read the article online

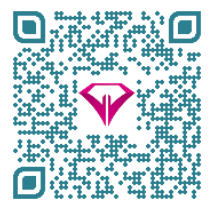

Corresponding Information:

Ehsan Saboory

Zanjan Metabolic Diseases Research Center, Zanjan University of Medical Sciences, Zanjan, Iran

E-Mail: : saboory@zums.ac.ir

\section{ABSTRACT}

Background \& Objective: Preeclampsia (PE) is a pregnancy complication with the signs of kidney damage. The effect of S-Allyl-cysteine (SAC) on inflammatory cytokines was evaluated to prevent PE-induced renal complications.

Materials \& Methods: Wistar rats were divided into seven groups: 1) control, 2) $\mathrm{PE}, 3) \mathrm{EC}$, 4) PE+SAC50, 5) PE+SAC200, 6) EC+SAC50, and 7) EC+SAC200. In Groups 1-3, the rats received saline by gavage for 9 consecutive days, starting on the day 11 of gestation (G11). In Groups 4-7, the rats received SAC (50 or $200 \mathrm{mg} / \mathrm{kg}$ ) by gavage for 9 days, starting on G11. The rats in PE and EC groups were injected with Lipopolysaccharides on G14. The rats in EC groups were injected with pentylenetetrazol (PTZ) on G16 and G18. On G20, urine, blood, and kidney samples were collected for biochemical analysis.

Results: In PE and EC groups, creatinine clearance, urine protein/creatinine ratio and proteinuria significantly increased compared to the control rats. Administration of SAC significantly reduced protein excretion and the protein/creatinine ratio in the urine specimen of all treated groups.

The results showed significant increase in the renal concentration of IL-1 $\beta$ and TNF$\alpha$ in the PE and EC rats. Administration of $200 \mathrm{mg} / \mathrm{kg} \mathrm{SAC}$ significantly decreased IL- $1 \beta$ and TNF- $\alpha$ in all treated groups. SAC $(200 \mathrm{mg} / \mathrm{kg})$ significantly decreased malondialdehyde and ameliorated histological changes in PE and EC groups; it also mitigated kidney dysfunctions in experimental PE and EC.

Conclusion: The ameliorative effect of SAC may be mediated by its antioxidant and modulatory effects on cytokines, such as IL- $1 \beta$ and TNF- $\alpha$.

Keywords: S-allyl cysteine, TNF- $\alpha$, IL-1 $\beta$, Kidney, Ppreeclampsia

\section{Introduction}

Preeclampsia (PE) is an important cause of maternal morbidity and mortality worldwide; it occurs in $2-8 \%$ of all pregnancies and complicates them (1). However, the causes of PE are not well documented, but placental abnormalities and maternal inflammatory responses to pregnancy are known to contribute to the pathogenesis of PE (2). PE is a pregnancy complication characterized by new-onset hypertension, proteinuria, edema and signs of damage to other organs system such as liver and kidneys.

In women with a history of normal blood pressure, $\mathrm{PE}$ usually develops after 20 weeks of gestation (1); when seizures develops, it is known as eclampsia (EC). PE is regarded as a two-stage process; the first stage is asymptomatic, marked by abnormal placentation and the release of placental factors into the maternal circulation. The second is a symptomatic stage, that leads to endothelial dysfunction and clinical syndromes, such as renal impairment and proteinuria (3). The kidneys are the main organs affected by PE. Therefore, assessment the amount of proteinuria and its causes is of critical significance (2).

Circulating cytokines are found to be elevated in maternal plasma during pregnancy (4). Local production of pro-inflammatory cytokines and the presence of such cytokines in the systemic circulation lead to a subclinical general inflammatory response in normal pregnancy. In $\mathrm{PE}$, inflammatory responses are exaggerated (5). Although the pathophysiological mechanisms responsible for the PE have not been clearly understood; maternal serum TNF- $\alpha$ and interleukins such as IL-6, play a major role in PE (6). The mentioned inflammatory cytokines are thought to link placental ischemia with the occurrence of 
renal dysfunction symptoms in PE (7). The circulating levels of TNF- $\alpha$ in PE are higher than those of gestational hypertension, suggesting an association between TNF- $\alpha$ levels and PE severity (8). Such elevations in pro-inflammatory cytokines could lead to endothelial dysfunction, which in turn leads to hypertension, increased total peripheral resistance and renal function alterations (9).

The occurrence of endothelial dysfunction in PE and other hypertensive disorders is associated with an increased endothelin-1, reactive oxygen species, and lipid peroxidation and decreased bioavailable nitric oxide (9). Antioxidants may play protective role in lipid peroxidation and PE prevention ; however, the prevention efficacy of antioxidants has not been confirmed yet (10).

S-Allyl cysteine (SAC) is a non-toxic and water-soluble compound of garlic (11). SAC has antioxidant property both in vivo and in vitro. Previous studies have shown the in vivo beneficial effects of SAC in numerous experimental studies; they have also mentioned to neuroprotective (12), renoprotective (13), hepatoprotective (14), and cardioprotective effects (15).

According to the above information, SAC may ameliorate PE-induced renal damages. The results of previous studies have demonstrated that aqueous extract of garlic with antioxidant properties, can ameliorate ischemiareperfusion (IR)-induced renal injury and oxidative stress (16). Thus, the current investigation aimed to examine the potential protective effect of SAC to prevent PE-induced renal complications.

\section{Materials and Methods}

\section{Study design}

Thirty-five female Wistar rats (10-week-old and weighing 200-240 g), with no pregnancy history were obtained from the animal facility of Urmia University of Medical Sciences, Urmia, Iran. The rats were kept in standard conditions as follows: $12 \mathrm{~h}$ normal light/dark cycle, $20-22^{\circ} \mathrm{C}$, and food and water ad libitum. All the rats were handled according to the Principles of Laboratory Animal Care (NIH publication No. 85-23, revised in 1985); the study was approved by the Ethics Committee of Urmia University of Medical Sciences (ethical code: IR.UMSU.REC.1395.209).

A week later, each female rat was mated with a sexual experienced male rat in a separate cage. The date of vaginal plaque formation was considered as the first day of pregnancy. Pregnant rats were divided into seven groups: 1) control group which received $1 \mathrm{ml}$ of normal saline by gavage for 9 consecutive days, starting on day 11 of gestation (G11) and an intraperitoneal (IP) injection of saline $(0.2 \mathrm{ml})$ on G14. The second group (PE) was treated like the control group, except that they received an injection of LPS $1 \mathrm{mg} / \mathrm{kg}$, IP (instead of saline) on G14. The third group (EC) was treated like the PE group in addition to pentylenetetrazol (PTZ) $40 \mathrm{mg} / \mathrm{kg}$ injection, IP on G16 and G18. The fourth (PE-SAC 50) and the fifth (PE-SAC 200) groups were treated as the PE group in addition to being gavaged with SAC (50 or 200 $\mathrm{mg} / \mathrm{kg} /$ day, respectively) for 9 days from G11 to G19, instead of saline. The last two groups (EC-SAC 50, and EC-SAC 200) were treated as the EC group, as well as being gavaged with SAC (50 or $200 \mathrm{mg} / \mathrm{kg} / \mathrm{day}$, respectively) for 9 days from G11 to G19.

As described above, the PE and EC experimental models were developed according to Huang Q methods (17). On G20, all the rats were anesthetized with ketamine $(60 \mathrm{mg} / \mathrm{kg})$ and xylazine $(20 \mathrm{mg} / \mathrm{kg})$. Urine samples were collected from the bladder by a syringe; blood was taken by puncturing the heart. The kidneys were dissected immediately. The right kidney was considered for histological experiments and kept in formalin. The left kidney was frozen and kept at $-80^{\circ} \mathrm{C}$ for MDA, IL-1B, and TNF$\alpha$ analysis.

\section{Serum and urine analysis}

Serum and urine were collected and kept frozen until biochemical analysis assay. Serum and urine BUN and creatinine were measured by an auto analyzer. Glomerular filtration rate (GFR) was calculated using the creatinine clearance equation. Urine protein and urine protein excretion (UPE) were measured by a commercial kit (Pars Azmoon, Iran). Furthermore, UPE was determined by a quantitative reaction with bromocresol green (BCG) (18), by means of the serum albumin of bovine as the standard. In order to measure the UPE, $10 \mu \mathrm{L}$ of the urine sample and standard were blended with $1 \mathrm{ml}$ of $\mathrm{BCG}$, then the absorbance was read at $625 \mathrm{~nm}$.

As it was mentioned before, the left kidneys were kept at $-80^{\circ} \mathrm{C}$ and then homogenized. The TNF- $\alpha$ amount of the homogenized kidney tissue was measured by an ELISA kit following the manufacturer's instructions (Glory Science Co., Ltd, China). About $100 \mathrm{mg}$ of renal tissue was homogenized in $1 \mathrm{~mL}$ of PBS and $0.05 \%$ Tween 20 . Then, the samples were centrifuged and the supernatant was immediately used for the ELISA assay. The lowest assay sensitivity of the kit was $2.13 \mathrm{ng} / \mathrm{L}$. Kidney tissue IL-1 $\beta$ was measured by the ELISA kit (Glory Science Co., Ltd, China), following the manufacturer's instructtions using standard diluent buffers designed for use with mouse serum or plasma.

To measure lipid peroxidation, the MDA amount of the homogenized kidney tissue was measured. Malondialdehyde-thiobarbituric (MDA-TBA) acid reactive substance levels were determined following the manufacturer's protocol (Zist Koshan TBARS Assay kit, Iran).

\section{Histopathological analysis}

The paraffin-embedded right kidney tissue samples were cut into 5- $\mu \mathrm{m}$-thick sections, and then used for Periodic Acid-Schiff's base (PAS) staining. PAS staining identifies matrix and basement membrane constituents.

\section{Data analysis}

Distribution of data was checked by the KolmogorovSmirnov test. The normally distributed data were analyzed by means of parametric methods. One-way analysis of variance (ANOVA) with post-hoc Tukey test was perfor- 
med for multiple comparisons. The results were expressed as mean \pm SEM, and $\mathrm{p}<0.05$ was considered as statistically significant.

\section{Results EC \\ Effect of SAC on kidney function test in PE and}

Kidney function was evaluated by measuring the kidney creatinine clearance, proteinuria, and the urine protein/creatinine ratio. As shown in Table 1, in PE and EC groups, creatinine clearance $(p<0.01$ and $p<0.001$, respectively), urine protein, and urine protein/creatinine ratio $(p<0.001)$ significantly increased compared to the healthy control rats. There was no significant difference in terms of creatinine clearance in $\mathrm{PE}+\mathrm{SAC} 50$ and $\mathrm{PE}+\mathrm{SAC} 200$ compared to PE rats.

Table 1. Urine protein, protein creatinine ratio, creatinine clearance and kidney tissue MDA content in control as well as PE and EC rats (with or without SAC treatment)

\begin{tabular}{|c|c|c|c|c|}
\hline Group & $\begin{array}{l}\text { Cr clearance } \\
(\mathrm{ml} / \mathrm{min} / \mathrm{g})\end{array}$ & $\begin{array}{l}\text { Urine protein } \\
\text { (mg/6h) }\end{array}$ & $\begin{array}{l}\text { Protein/ Creatinine } \\
\text { (mg/mg) }\end{array}$ & $(\mathrm{nmol} / \mathrm{ml})$ \\
\hline Control & $0.85 \pm 0.04$ & $18.8 \pm 6$ & $0.38 \pm 0.08$ & $41.3 \pm 4.4$ \\
\hline PE & $1.20 \pm 0.1^{* *}$ & $532.3 \pm 91.3^{* * *}$ & $13.9 \pm 1.4^{* * *}$ & $51.4 \pm 7.6$ \\
\hline EC & $1.26 \pm 0.16^{* * *}$ & $834.5 \pm 149.7^{* * *}$ & $23.7 \pm 2.6^{* * *}$ & $57.2 \pm 10.9^{* *}$ \\
\hline PE+SAC50 & $1.04 \pm 0.06$ & $169.6 \pm 20^{\# \# \#, \dagger \dagger}$ & $4.4 \pm 0.6^{\# \# \#, \dagger \dagger}$ & $42.1 \pm 4.4$ \\
\hline PE+SAC200 & $0.99 \pm 0.14$ & $128.4 \pm 25.3^{\# \# \#, \dagger \dagger}$ & $3.1 \pm 0.5^{\# \#, \dagger}$ & $39.2 \pm 2.5$ \\
\hline EC+SAC50 & $0.98 \pm 0.12^{\dagger}$ & $198.2 \pm 41.9^{\dagger \dagger, \# \# \# ~}$ & $4.5 \pm 0.6^{\dagger \%, \ldots \# \#}$ & $45.5 \pm 3.8^{\dagger}$ \\
\hline $\mathrm{EC}+\mathrm{SAC200}$ & $0.94 \pm 0.1^{\dagger \dagger \#}$ & $165.6 \pm 19.3^{\dagger \dagger, \ldots \# \#}$ & $3.5 \pm 0.06^{\dagger \dagger, \ldots \# \#}$ & $43.1 \pm 3.1^{\dagger}$ \\
\hline
\end{tabular}

The values are presented as mean \pm SE; PE (preeclampsia), EC (eclampsia), SAC (S-allyl cysteine), MAD (malondialdehyde); $*, \dagger$, and \# show the significance compared to the control, PE, and EC groups, respectively; $(*,+$, and \# indicate $\mathbf{p}<0.05 ; * *,+\dagger$, and \#\# show $\mathbf{p}<0.01 ; * * *,+\dagger+$, and \#\# designate $\mathbf{p}<0.001$ )

SAC200 mg/kg significantly $(\mathrm{p}<0.01)$ reversed the ECinduced alterations in creatinine clearance and urine protein/creatinine ratio changes. Proteinuria significantly increased in $\mathrm{PE}$ and $\mathrm{EC}$ rats compared to the control rats $(\mathrm{p}<0.001)$. Nevertheless, the administration of 50 and 200 $\mathrm{mg} / \mathrm{kg}$ SAC significantly reduced 6-h UPE compared to $\mathrm{PE}$ and EC groups $(\mathrm{p}<0.001)$.

Effect of SAC on kidney tissue MDA in PE and EC rats

As shown in Table 1, kidney MDA content as a marker of lipid peroxidation was significantly higher in EC rats compared to the control group $(p<0.01)$. There was no significant difference in MDA content between PE and healthy control rats $(\mathrm{p}=0.15)$. Administration of SAC (50 and $200 \mathrm{mg} / \mathrm{kg}$ ) resulted in a significant reduction in lipid peroxidation of EC rats $(\mathrm{p}<0.05)$.

\section{Effect of SAC on the kidney level of TNF- $\alpha$ in PE} and EC

The kidney tissue content of TNF- $\alpha$ significantly increased in $\mathrm{PE}$ and $\mathrm{EC}$ rats compared to the healthy control group $(p<0.001)$. SAC $200 \mathrm{mg} / \mathrm{kg}$ significantly prevented TNF- $\alpha$ elevation in PE and EC rats $(p<0.01)$. Also, SAC $50 \mathrm{mg} / \mathrm{kg}$ significantly decreased kidney TNF$\alpha$ only in EC rats $(p<0.05)$, but the effect was nonsignificant in the PE group (as shown in Fig. 1).

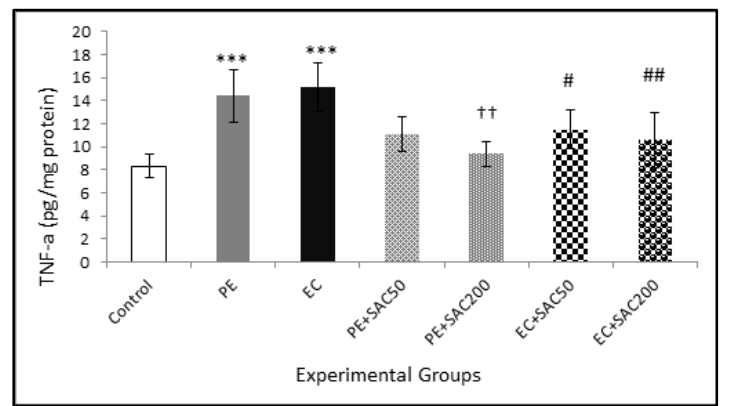

Figure 1. Tumor necrosis factor-alpha (TNF- $\alpha$ ) concentration in kidney tissue homogenate; the values are expressed as Mean \pm SE; PE (preeclampsia), EC (eclampsia), SAC (S-allyl cysteine); * $\uparrow$, and \# show the significance level compared to the control, PE and EC groups, respectively; (*, $\dagger$, and \# indicate $\mathbf{p}<0.05 ; * *, \dagger \dagger$ and \#\# show $\mathbf{p}<0.01 ; * * *, \dagger \dagger \dagger$ and \#\# designate $\mathbf{p}<0.001$ ).

\section{Effect of SAC on the kidney level of IL1- $\beta$ in PE and $\mathrm{EC}$}

As displayed in Fig. 2, kidney tissue IL1- $\beta$ significantly increased in $\mathrm{PE}$ and $\mathrm{EC}$ rats compared to the healthy control $(p<0.01)$. SAC administration at both doses of 50 and $200 \mathrm{mg} / \mathrm{kg}$ significantly attenuated the changes in kidney IL1- $\beta$ in EC rats $(p<0.01)$. In PE rats, only the 200 $\mathrm{mg} / \mathrm{kg}$ dose of SAC significantly declined kidney IL1- $\beta$ $(\mathrm{p}<0.01)$. 


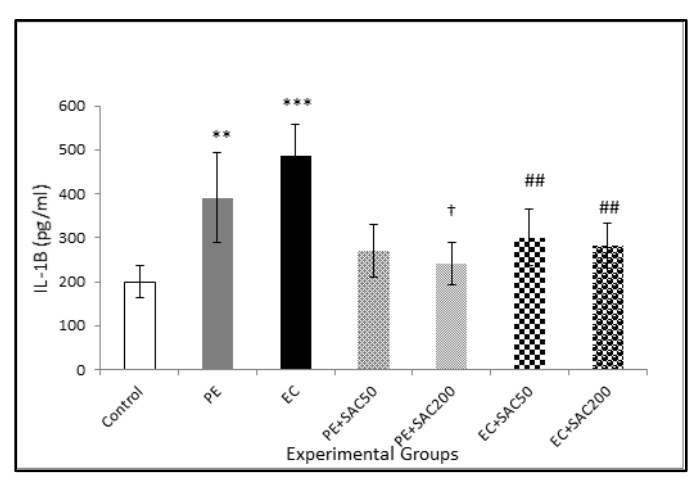

Figure 2. Concentration of interleukin 1 beta (IL 1ß) in kidney tissue homogenate; the values are expressed as Mean $\pm \mathrm{SE}$; PE (preeclampsia), EC (eclampsia), SAC(S-allyl cysteine); $*,+$, and \# show the significance compared to the control, PE, and EC groups, respectively; $(*, \dagger$ and \# indicate $\mathbf{p}<0.05 ; * *$, $\dagger$ and \#\# show p<0.01; ***, $\dagger \dagger$ and \#\# designate $\mathbf{p}<0.001$ ).

\section{Effect of SAC on kidney morphological changes in $\mathrm{PE}$ and $\mathrm{EC}$}

$\mathrm{PE}$ and EC led to alterations in area of glomerular surface, mesangial expansion and moderate condensing of the glomerular basement membrane (Fig. 3). The accumulation of glomerular matrix augmented in $\mathrm{PE}$ and EC rats compared to the control. Treatment with 50 and $200 \mathrm{mg} / \mathrm{kg}$ of SAC significantly reduced mesangial expansion. There was no significant difference between the effect of 50 and $200 \mathrm{mg} / \mathrm{kg}$ of SAC in this regard. As shown in Fig. 3, PE- and EC-induced pathological changes in kidneys were significantly alleviated in the SAC-treated rats

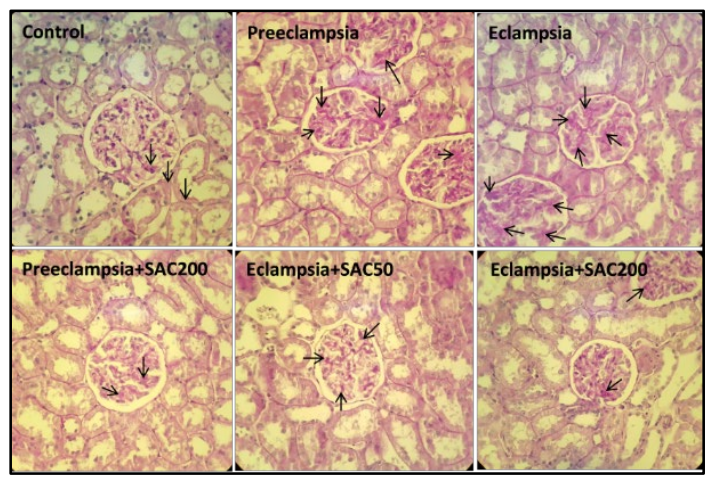

Figure 3. Photomicrographs of PAS staining of renal tissues; SAC (S-allyl cysteine); arrows show the mesangial matrix accumulation in nuclei-free areas of the mesangium in glomeruli (Magnification: $\times 400$ )

\section{Discussion}

In this study, the potential protective effects of SAC to prevent renal complications associated with $\mathrm{PE}$ and EC were investigated. The results revealed that $\mathrm{PE}$ and EC caused a significant increase in creatinine clearance, proteinuria and the protein/creatinine ratio. Administration of SAC significantly prevented PE-induced kidney functional alterations. Although the etiopathology of urinary protein excretion in PE and EC has not been still entirely understood; the most often suggested mechanisms in this regard are the likely rises in capillary pressure of glomerulus, adjustments in glomerular filtration barrier selectivity, and changes in proximal tubular reabsorption $(19,20)$.

Michael Cackovic et al. (2008) reported, that loss of glomerular filter charge selectivity in PE led to increased excretion of total proteins, but reduced relative excretion of TNF- $\alpha$. PE is linked with decreased clearance of TNF- $\alpha$ compared to other proteins, regardless of increased systemic levels (21). Placental changes set up the key factors accountable for the development of the disease and its harshness (22). TNF- $\alpha$ is the potent cytokine in PE, which is likely a consequence of the pathophysiological changes linked with severe PE. In this regard, systemic level of this protein plays a key role in starting and preserving the pathophysiologic mechanism of PE. Furthermore, the degree of kidney damage that characterizes severe PE may be an important regulator of the systemic TNF- $\alpha$ levels.

Some studies have shown an aberrant lymphocyte Th1/Th2 cytokine balance in PE. Cytokines such as IL4 , IL-10 and TNF- $\alpha$ induce an overstated maternal systemic response of inflammation, characterized by hypertension and proteinuria $(23,24)$. Overall, the results of the present study are consistent with those of the previous studies, which have reported higher level of TNF- $\alpha$ in PE compared to the uncomplicated pregnancies; kidney structural and functional anomalies have been also reported as a result of TNF- $\alpha$ elevation $(8,25)$.

In pregnancy, a more violent inflammatory reaction occurs after PE and EC. To date, no exact mechanism underlying the changes in the glomerulus of the animal model of PE and EC has been reported. Various stimuli such as TNF- $\alpha$ and IL-1 $\beta$, which released by activated macrophages (26) can change the glomerular filtration barrier (27). Leukocytes and intrinsic renal cells could be the source of intra-renal and circulating TNF- $\alpha$ (28).

The results of the present study indicated significant increase in TNF- $\alpha$ and IL- $1 \beta$ in the kidney tissue after PE and EC induction by LPS administration, suporting a generalized inflammatory condition in PE and EC. Treatment with SAC significantly reversed TNF- $\alpha$ and IL- $1 \beta$ alterations in the kidney tissue. A few studies have previously examined serum IL-1 $\beta$ levels during PE (29). Kalinderis et al. (2011) reported significant elevated level of serum IL-1 $\beta$ in PE, highlighting the inflammatory background of PE (30). Consistent with the present study, they showed that intrinsic renal cells are the major source of IL- $1 \beta$ synthesis, and also IL- $1 \beta$ can induce mesangial cell proliferation and extracellular matrix production in normal and disease rat kidney (31).

Previous studies have shown that IL- $1 \beta$ is the major pro-inflammatory cytokine-mediating glomerular inj- 
ury (32). The findings of the present study are in line with those of prior reports, which reported that SAC pretreatment of LPS-challenged mice dose-dependently mitigates inflammatory cytokines in the kidney tissue (33). Another animal models have been confirmed the nephroprotective effects of SAC on nephronpathies such as cyclosporine A (CsA)-induced nephrontoxicity (34), ischemia and reperfusion-induced renal damage (35).

As mentioned before, although the exact etiology and pathogenesis of PE still remain obscure, it is now unanimously accepted that inflammation and oxidative stress caused by placental dysfunction are a common underlying cause of PE (36). The antioxidant properties of garlic and some garlic-derived compounds including SAC, such as its well-known capability to scavenge reactive oxygen species, lipid peroxidation inhibition (12) and block the $\mathrm{H}_{2} \mathrm{O}_{2}$-induced NF-kB activation are well recognized (37). Moreover, it has also been suggested that the antioxidant mechanisms of SAC are related to an increased amount of the endogenous antioxidant of reduced glutathione (12).

Recent evidence suggests that human PE is an endothelial cell disorder, due to toxic oxygen injury (38). Our results demonstrated that the LPS-induced EC in rats significantly increased the kidney tissue MDA content as a reliable index of lipid peroxidation, while treatment with SAC significantly decreased the MDA content of the kidney. However, the ameliorative effect of SAC treatment in LPS-induced EC and renal injury may be due to an increase in antioxidant capacity. A previous study reported an increase in kidney MDA content following endotoxin administration (33). The histological analysis of the present study revealed that both PE and EC might affect the kidney of adult rats by disorganization of the glomerulus and matrix mesangial expansion. Moreover, in this experimental model for PE, microvasculature damage is inevitable, at least in the glomerular microvansculature. The results of the histological studies confirmed the LPS-induced biochemical changes. Furthermore, SAC administration reversed PE and ECinduced renal complications.

\section{Conclusion}

Taken together, SAC is capable of alleviating LPSinduced PE and EC renal complications through mitigation of renal oxidative stress and inflammation; its favorable effect exhibits a dose-dependent pattern. Clinical investigations may prove that SAC has beneficial effects on human PE.

\section{Statement of Ethics}

All the rats were handled based on the Principles of Laboratory Animal Care (NIH publication No. 85-23, revised in 1985), and the study was approved by the
Ethics Committee of Urmia University of Medical Sciences, Urmia, Iran.

\section{Acknowledgments}

None.

\section{Conflict of Interest}

The authors have no conflict of interest to declare.

\section{Funding Sources}

This study was supported by the Urmia University of Medical Sciences, Urmia, Iran.

\section{References}

1. Karumanchi SA, Maynard SE, Stillman IE, Epstein FH, VP. S. Pre-eclampsia: A renal perspective. Kidney Int. 2005;67:2101-13. [DOI:10.1111/j.15231755.2005.00316.x]

2. Piccoli GB, Mannucci C. Preeclampsia: A diagnosisnondiagnosis that is too easily made: The case of primary hyperaldosteronism. Kidney Blood Pressure Res. 2020;45(3):363-7. [DOI:10.1159/000507116]

3. Zelinka T, Petrák O, Rosa J, Holaj R, Strauch B, Widimský J. Primary aldosteronism and pregnancy. Kidney Blood Pressure Res. 2020;45(2):275-85. [DOI:10.1159/000506287]

4. Lewis DF, Canzoneri BJ, Wang Y. Maternal circulating TNF- $\alpha$ levels are highly correlated with IL10 levels, but not IL-6 and IL-8 Levels, in Women with Pre-Eclampsia. Am J Reprod Immunol. 2009;62(5):269-74. [DOI:10.1111/j.16000897.2009.00735.x]

5. Hauth JC, Ewell MG, Levine RJ, et al. Pregnancy outcomes in healthy nulliparas who developed hypertension. Obstet Gynecol. 2000;95(1):24-8. [DOI:10.1016/S0029-7844(99)00462-7]

6. Kupferminc MJ, Peaceman AM, Wigton TR, Rehnberg KA, Socol ML. Tumor necrosis factor- $\alpha$ is elevated in plasma and amniotic fluid of patients with severe preeclampsia. Am J Obstet Gynecol 1994;170(6):1752-9. [DOI:10.1016/S00029378(94)70351-5]

7. Tosun M, Celik H, Avci B, Yavuz E, Alper T, Malatyalioğlu E. Maternal and umbilical serum levels of interleukin-6, interleukin-8, and tumor necrosis factor- $\alpha$ in normal pregnancies and in pregnancies complicated by preeclampsia. J Matern Fetal Neonatal Med. 2010;23(8):880-6 [DOI:10.3109/14767051003774942]

8. Peraçoli JC, Rudge MVC, Peraçoli MTS. Tumor necrosis factor-alpha in gestation and puerperium of women with gestational hypertension and preeclampsia. Am J Reprod Immunol 2007;57(3):177-85. [DOI:10.1111/j.1600-0897.2006.00455.x] 
9. Gilbert JS, Ryan MJ, LaMarca BB, Sedeek M, Murphy SR, Granger JP. Pathophysiology of hypertension during preeclampsia: linking placental ischemia with endothelial dysfunction. Am J Physiol Heart Circ Physiol. 2008;294(2):H541-H50. [DOI:10.1152/ajpheart.01113.2007]

10. Polyzos NP, Mauri D, Tsappi M, et al. Combined vitamin $\mathrm{C}$ and $\mathrm{E}$ supplementation during pregnancy for preeclampsia prevention: a systematic review. Obstet Gynecol Surv. 2007;62(3):202-6. [DOI:10.1097/01.ogx.0000256787.04807.da]

11. Patel M, Sachan R, Gangwar R, Sachan P, Natu S. Correlation of serum neutrophil gelatinase-associated lipocalin with acute kidney injury in hypertensive disorders of pregnancy. Int J Nephrol Renovasc Dis. 2013;6:181-6. [DOI:10.2147/IJNRD.S45523]

12. Numagami Y, Ohnishi ST. S-allylcysteine inhibits free radical production, lipid peroxidation and neuronal damage in rat brain ischemia. $J$ Nutr. 2001;131(3):1100S-5S.

[DOI:10.1093/jn/131.3.1100S]

13. Maldonado PD, Barrera D, Rivero I, et al. Antioxidant S-allylcysteine prevents gentamicin-induced oxidative stress and renal damage. Free Radic Biol Med 2003;35(3):317-24. 5849(03)00312-5]

14. Hsu CC, Lin CC, Liao TS, Yin MC. Protective effect of s-allyl cysteine and s-propyl cysteine on acetaminophen-induced hepatotoxicity in mice. Food Chem Toxicol. 2006;44(3):393-7. [DOI:10.1016/i.fct.2005.08.012]

15. Mostafa MG, Mima T, Ohnishi ST, Mori K. Sallylcysteine ameliorates doxorubicin toxicity in the heart and liver in mice. Planta Medica. 2000;66(02):148-51. [DOI:10.1055/s-2000-11124]

16. Kabasakal L, Şehirli Ö, Çetinel Ş, Cikler E, Gedik N, Şener G. Protective effect of aqueous garlic extract against renal ischemia/reperfusion injury in rats. J Med Food [DOI:10.1089/jmf.2005.8.319]

2005;8(3):319-26.

17. Huang Q, Liu L, Hu B, Di X, Brennecke SP, Liu H. Decreased seizure threshold in an eclampsia-like model induced in pregnant rats with lipopolysaccharide and pentylenetetrazol treatments. PLoS One. 2014;9(2):e89333-e. [DOI:10.1371/journal.pone.0089333]

18. Müller K, Brunnberg L. Determination of plasma albumin concentration in healthy and diseased turtles: A comparison of protein electrophoresis and the bromcresol green dye-binding method. Vet Clin Pathol 2009;39:79-82. [DOI:10.1111/j.1939165X.2009.00177.X]

19. Chan P, Brown M, Simpson JM, Davis G. Proteinuria in pre-eclampsia: how much matters? An Int J Obstet Gynaecol. 2005;112(3):280-5. [DOI:10.1111/j.1471-0528.2004.00395.x]

20. Demirci O, Kumru P, Arınkan A, et al. Spot protein/creatinine ratio in preeclampsia as an alternative for 24-hour urine protein. Balkan Med J.
2015;32(1):51

[DOI:10.5152/balkanmedj.2015.15447]

21. Cackovic M, Buhimschi CS, Zhao G, et al. Fractional excretion of tumor necrosis factor- $\alpha$ in women with severe preeclampsia. Obstet Gynecol. 2008;112(1):93. [DOI:10.1097/AOG.0b013e31817c4304]

22. Silasi M, Cohen B, Karumanchi SA, Rana S. Abnormal placentation, angiogenic factors, and the pathogenesis of preeclampsia. Obstet Gynecol Clin North Am. 2010;37(2):239-53.

[DOI:10.1016/j.ogc.2010.02.013]

23. Rusterholz C, Hahn S, Holzgreve W. Role of placentally produced inflammatory and regulatory cytokines in pregnancy and the etiology of preeclampsia. Semin Immunopathol 2007;29(2):15162. [DOI:10.1007/s00281-007-0071-6]

24. Benyo DF, Miles TM, Conrad KP. Hypoxia stimulates cytokine production by villous explants from the human placenta. J Clin Endocrinol Metab. 1997;82(5):1582-8. [DOI:10.1210/jc.82.5.1582]

25. Hayashi M, Ueda $Y$, Yamaguchi $T$, et al. Tumor necrosis factor- $\alpha$ in the placenta is not elevated in preeclamptic patients despite its elevation in peripheral blood. Am J Reprod Immunol. 2005;53(3):113-9. [DOI:10.1111/j.1600-0897.2005.00253.x]

26. Parameswaran N, Patial S. Tumor necrosis factor- $\alpha$ signaling in macrophages. Crit Rev Eukaryot Gene Expr. 2010;20(2):87-103. [DOI:10.1615/CritRevEukarGeneExpr.v20.i2.10 ]

27. Xu C, Wu X, Hack BK, Bao L, Cunningham PN. TNF causes changes in glomerular endothelial permeability and morphology through a Rho and myosin light chain kinase-dependent mechanism. Physiol Rep. 2015;3(12):e12636. [DOI:10.14814/phy2.12636]

28. Neale TJ, Rüger BM, Macaulay $\mathrm{H}$, et al. Tumor necrosis factor-alpha is expressed by glomerular visceral epithelial cells in human membranous nephropathy. Am J Pathol. 1995;146(6):1444-54.

29. Visser N, van Rijn BB, Rijkers GT, Franx A, Bruinse HW. Inflammatory changes in preeclampsia: current understanding of the maternal innate and adaptive immune response. Obstet Gynecol Surv. 2007;62(3):191-201.

[DOI:10.1097/01.ogx.0000256779.06275.c4]

30. Kalinderis M, Papanikolaou A, Kalinderi K, et al. Elevated serum levels of interleukin-6, interleukin-1 $\beta$ and human chorionic gonadotropin in pre-eclampsia. Am J Reprod Immunol. 2011;66(6):468-75. [DOI:10.1111/j.1600-0897.2011.01019.x]

31. Niemir ZI, Stein H, Dworacki G, et al. Podocytes are the major source of IL- $1 \alpha$ and IL- $1 \beta$ in human glomerulonephritides. Kidney Int. 1997;52(2):393403. [DOI:10.1038/ki.1997.346]

32. Zhang W, Li Q, Wang L, Yang X. Simvastatin ameliorates glomerulosclerosis in Adriamycininduced-nephropathy rats. Pediatr Nephrol. 2008;23(12):2185-94. [DOI:10.1007/s00467-0080933-8] 
33. Khajevand-Khazaei M-R, Azimi S, Sedighnejad L, Salari S, Ghorbanpour A, Baluchnejadmojarad T, et al. S-allyl cysteine protects against lipopolysaccharideinduced acute kidney injury in the C57BL/6 mouse strain: Involvement of oxidative stress and inflammation. Int Immunopharmaco. 2019;69:19-26. [DOI:10.1016/j.intimp.2019.01.026]

34. Magendiramani V, Umesalma S, Kalayarasan S, Nagendraprabhu P, Arunkumar J, Sudhandiran G. Sallylcysteine attenuates renal injury by altering the expressions of iNOS and matrix metallo proteinase-2 during cyclosporine-induced nephrotoxicity in Wistar rats. J Appl Toxicol 2009;29(6):522-30. [DOI:10.1002/jat.1437]

35. Segoviano-Murillo S, Sánchez-González DJ, Martínez-Martínez CM, Cruz C, Maldonado PD, Pedraza-Chaverrí J. S-allylcysteine ameliorates ischemia and reperfusion induced renal damage. Phytother Res. 2008;22(6):836-40. [DOI:10.1002/ptr.2396]
36. Faas MM, Schuiling GA, Linton EA, Sargent IL, Redman CW. Activation of peripheral leukocytes in rat pregnancy and experimental preeclampsia. Am J Obstet Gynecol. 2000;182(2):351-7. [DOI:10.1016/S0002-9378(00)70223-7]

37. Ide N, Lau BH. Garlic compounds minimize intracellular oxidative stress and inhibit nuclear factor$\kappa B$ activation. J Nutr. 2001;131(3):1020S-6S [DOI:10.1093/jn/131.3.1020S]

38. Stark J. Pre-eclampsia and cytokine induced oxidative stress. An Int J Obstet Gynaecol. 1993;100(2):105-9. [DOI:10.1111/j.1471-0528.1993.tb15203.x]

\section{How to Cite This Article:}

Abdollahzade Fard A, Saboory E, Biabangard A, Amini M. S-Allyl Cysteine Mitigates Kidney Dysfunctions in the Rat Models of Preeclampsia and Eclampsia: The Possible Role of TNF- $\alpha$ and IL1- $\beta$. J Adv Med Biomed Res. 2021; 29 (137): 324-330

\section{Download citation:}

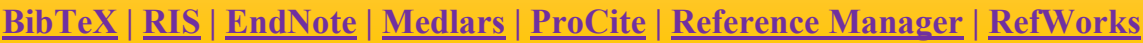

\section{Send citation to:}

(30) Mendeley 2 Zotero (i)RefWorks $\underline{\text { RefWorks }}$ 